\title{
A Direct Regression Approach to Decomposing Socioeconomic Inequality of Health
}

\begin{abstract}
This paper presents a new regression-based decomposition of socioeconomic inequality of health that is more direct than other approaches. The method can be applied to both rank-dependent and level-dependent indicators of inequality. The response variable of our regression model is a simple reformulation of the measure of overall performance of an individual in the health and socioeconomic domains. Regression results are described in terms of marginal effects of the explanatory variables, but also in terms of their logworths or importance values. We illustrate our method, and compare it with alternatives, using Australian health and income data.
\end{abstract}

Keywords: Bivariate inequality, Socioeconomic health inequality, Decomposition

This is the author manuscript accepted for publication and has undergone full peer review but has not been through the copyediting, typesetting, pagination and proofreading process, which may lead to differences between this version and the Version of Record. Please cite this article as doi: 10.1002/hec.3891

This article is protected by copyright. All rights reserved. 


\section{Introduction}

Research on the measurement of socioeconomic inequality of health is increasingly focused on the identification of the factors that contribute to this type of inequality and account for its evolution over time. Various decomposition techniques have been proposed to better understand and explain the observed levels of inequality at a given time for a given country and in comparisons over time and across countries. Some of these techniques have been reproduced from well-known results in the fields of inequality measurement (e.g., Rao, 1969; Bourguignon, 1979; Shorrocks, 1980) and labour economics (e.g., Blinder, 1973; Oaxaca, 1973). Others have been developed specifically for the analysis of bivariate inequality (e.g., Wagstaff, Van Doorslaer and Watanabe, 2003; Clarke, Gerdtham and Connelly, 2003; Wagstaff, 2005b; Abul Naga and Geoffard, 2006; Van Ourti, Van Doorslaer and Koolman, 2009; Makdissi, Sylla and Yazbeck, 2013; Allanson and Petrie, 2013). Van Doorslaer and Van Ourti (2011), O'Donnell, Van Doorslaer and Wagstaff (2012), and Van Ourti, Erreygers and Clarke (2014) provide useful overviews of the state of the art on the analysis of socioeconomic inequality of health.

Almost all of this work is centered around rank-dependent indicators of inequality, which are the dominant measures of socioeconomic inequality of health. They are defined in terms of the ranks of the socioeconomic variable and the levels of the health variable. Recently, however, Erreygers and Kessels (2017) argued in favour of using level-dependent indicators which are based on the levels of both the socioeconomic and the health variable and therefore capture more information.

In empirical analyses of socioeconomic inequality of health, the regressionbased decomposition methods proposed by Wagstaff, Van Doorslaer and Watanabe (2003), henceforth referred to as WDW, have become widely used. The WDW framework was developed with the aim of studying three types of questions: (i) What are the causes of socioeconomic inequality of health in a given society at a given moment of time? (ii) What explains the differences between societies and the changes over time in socioeconomic inequality? and (iii) What is the effect of policy changes? Here we focus exclusively on the first of these issues. The study of differences, changes and policy impacts, often based on Oaxaca-Blinder decomposition techniques, is beyond the scope of our paper. With regard to the determination of the causes of socioeconomic inequality of health, the WDW approach consists of two steps: the first is to run a regression in order to identify the factors deemed to be related to health; the second is to assess to what extent the associations of these factors with socioeconomic status contribute to the observed level of socioeconomic inequality. It is important to note that in the first step only the 
covariates of health are explored; those of socioeconomic status are ignored. For this reason we have characterized the WDW decomposition method as 'one-dimensional'. To recognize the bivariate nature of rank-dependent indicators, Erreygers and Kessels (2013) presented various two-dimensional decomposition methods, where the covariates of both health and socioeconomic rank were considered. Using structural equation modeling, Kessels and Erreygers (2016) even introduced a feedback mechanism between the two indicator variables. As shown in these papers, the decomposition results may differ substantially according to the specific regression-based method one adopts.

In recent years, decomposition techniques based on recentered influence function (RIF) regression have been developed as alternatives. These techniques have a wide range of applications (see Firpo, 2007), and have been used to analyse inequality and poverty (see, e.g., Essama-Nssah and Lambert, 2012, 2016). Heckley, Gerdtham and Kjellsson (2016) were the first to formulate a general RIF regression framework for the decomposition of rankdependent indicators of socioeconomic inequality of health. Rather than being based on a regression of health and/or socioeconomic status, this method focuses on the influence that each observation of the two variables has on the indicator. First, a vector of individual RIF values is computed, expressing every individual's influence on the indicator. Next, these RIF values are regressed on a set of explanatory variables using OLS, yielding the marginal effects of the variables on the influence they exert on the indicator.

In this paper we propose a direct regression approach that concentrates on the individual components of the indicator rather than on the influences. Our method exploits the fact that the indicator can be reformulated as the mean of a composite variable which measures the joint outcome in the two dimensions of interest. This variable compares each individual's performance with respect to health and socioeconomic position to the average attainments in these domains. The decomposition is based on the regression of the composite variable on the explanatory variables. Similar to the RIF decomposition, we describe the regression results in terms of the marginal effects of the explanatory variables on the response.

The introduction of this new and simple regression-based method for the decomposition of socioeconomic inequality of health is the major contribution of our paper. We highlight the differences between our method and the two other regression-based approaches, WDW and RIF. In addition, we introduce the logworth statistic as a means to assess the importance of the explanatory variables in each of the regressions.

We start by presenting and briefly comparing the indices of socioeconomic inequality of health we are considering here. Next, we discuss the WDW and 
RIF regression approaches for decomposition analysis as well as our new and more direct regression approach. We illustrate our method and compare it to the current approaches using an empirical study of income-related health inequality in Australia.

\section{Indices of Socioeconomic Inequality of Health}

\subsection{Basic Notation and Assumptions}

For a population of $n$ individuals $(i=1,2, \ldots, n)$ we observe the levels each person attains in the socioeconomic $\left(y_{i}\right)$ and health $\left(h_{i}\right)$ domains. For convenience, we designate socioeconomic achievement as "income", but it goes without saying that socioeconomic status can be measured in a variety of ways (by consumption levels, by years of education, etc.). We assume that both $y_{i}$ and $h_{i}$ are ratio-scale variables with well-defined lower bounds greater than or equal to 0 . Income is typically an unbounded variable. Health, by contrast, is often a bounded variable and possibly of the binary type.

Our formulas for the rank- and level-dependent indices will be expressed in terms of relative incomes and relative fractional ranks. The relative income of an individual $\widetilde{y}_{i}$ is the ratio of this individual's income to average income $\mu_{y}$. We denote the rank of individual $i$ in the income distribution as $r_{i}$. If there are no ties in the income distribution, the rank of the poorest person in society is equal to 1 , that of the second poorest person equal to 2 , etc. If a group of $k+1$ individuals are tied in position $g$, the rank of each of these individuals is equal to $g+(k / 2)$. For simplicity, however, we assume there are no ties in the income distribution, and that individuals are ranked according to their incomes. ${ }^{1}$ The fractional rank $f_{i}$ is defined as $f_{i} \equiv \frac{1}{n}\left(r_{i}-\frac{1}{2}\right)$, and varies between $\frac{1}{2 n}$ and $1-\frac{1}{2 n}$. The average fractional rank is $\mu_{f}=\frac{1}{2}$. The relative fractional rank $\tilde{f}_{i}$ is the fractional rank divided by its average, i.e. $\widetilde{f}_{i}=2 f_{i}$, and varies between $\frac{1}{n}$ and $2-\frac{1}{n}$.

\subsection{Bivariate Linear Indices}

The indices of bivariate inequality considered in this paper belong to a broad class of linear inequality measures. These indices are closely related to the family of linear measures of univariate inequality defined by Mehran (1976). We focus on bivariate indices where income serves as the weighting variable

\footnotetext{
${ }^{1}$ Appendix A specifies how the formulas must be adapted when there are ties, and when not all individuals have the same population weight. In footnote 5 of Section 3.2 we explain how the RIFs must be defined in the presence of income ties.
} 
and health as the weighted variable. In formal terms, the absolute version of these indices takes the following form ${ }^{2}$ :

$$
I(y, h)=\frac{1}{n} \sum_{i=1}^{n} w_{i}(y) h_{i}
$$

The relative version of our indices is obtained by dividing the index by the mean of the weighted variable:

$$
I^{r}(y, h)=\frac{I(y, h)}{\mu_{h}}
$$

Other versions of the indices have been proposed in the literature, e.g. in order to deal with binary variables (Wagstaff, 2005a; Erreygers and Van Ourti, 2011). For bounded variables, whether they are binary or of another type, we suggest the use of the index proposed by Erreygers (2009):

$$
I^{b}(y, h)=\frac{A}{\left(h_{\max }-h_{\min }\right)} I(y, h)
$$

where $h_{\min }$ and $h_{\max }$ stand for the lower and upper bounds of the health variable, and $A$ is a constant.

\subsection{Rank-Dependent Indices}

Rank-dependent indices rely exclusively on income ranks to define the weights $w_{i}(y)$; no other information on the income distribution enters into the calculation of the weights. There exists a great variety of these indices, expressing different degrees of distributional sensitivity (Erreygers, Clarke and Van Ourti, 2012). In this paper we limit ourselves to indices which are characterized by a weighting function which is linear in the relative fractional income ranks $\widetilde{f}_{i}$. This weighting function and the associated bivariate index $R$ are defined as follows:

$$
\begin{gathered}
w_{i}^{R}=\tilde{f}_{i}-1 \\
R=\frac{1}{n} \sum_{i=1}^{n} w_{i}^{R} h_{i}
\end{gathered}
$$

The weights $w_{i}^{R}$ steadily increase as $\widetilde{f}_{i}$ goes from (almost) 0 to (almost) 2 . If the group of the 'poor' is defined as those who have negative weights and the

\footnotetext{
${ }^{2}$ If there is no confusion possible, we will drop the arguments and simply write $I$ instead of $I(y, h)$, etc.
} 
group of the 'rich' as those who have positive weights, the weighting function (4) puts the boundary between the two groups exactly in the middle of the population. Those with relative fractional ranks smaller than 1 have negative weights, and those with relative fractional ranks larger than 1 positive weights. The negative weights sum to $-n / 4$ and the positive weights to $n / 4 .^{3}$ This motivates the choice of $A=4$ for the bounded version of the rank-dependent index, as suggested by Erreygers (2009). The relative version of the index is equal to the standard Concentration Index.

\subsection{Level-Dependent Indices}

In contrast to rank-dependent indices, the weights of level-dependent indices are based upon income levels rather than income ranks. Also for leveldependent indices different versions can be defined (Erreygers and Kessels, 2017), but here we consider only the basic version $L$ characterized by a weighting function which is a simple linear function of relative income ${ }^{4}$ :

$$
\begin{gathered}
w_{i}^{L}=\widetilde{y}_{i}-1 \\
L=\frac{1}{n} \sum_{i=1}^{n} w_{i}^{L} h_{i}
\end{gathered}
$$

The weights $w_{i}^{L}$ are proportional to the deviations of the incomes from the mean. If there is a high degree of income inequality as shown by a positively skewed income distribution, typically there will be a lot of individuals with income levels below the mean, who will therefore have negative, but in absolute terms rather small weights. On the other side of the spectrum, those who have very high incomes will have positive, and in absolute terms quite large weights. Hence, a small change in the health level of a relatively well-off individual will probably have a more pronounced influence on the index than a comparable change in the health level of an individual who is less well-off.

All the negative weights sum to $-(n / 2) M$, and all the positive weights to $(n / 2) M$, where $M$ stands for the Mean Absolute Deviation of $\widetilde{y}$ :

$$
M=\frac{1}{n} \sum_{i=1}^{n}\left|\widetilde{y}_{i}-1\right|
$$

\footnotetext{
${ }^{3}$ Strictly speaking, this result holds only when $n$ is even. When $n$ is odd, the sum of the negative weights is $-[(n-1)(n+1)] /(4 n)$, which for large $n$ is approximately equal to $-n / 4$. And similarly for the positive weights.

${ }^{4}$ The $L$ index is related to the $\kappa$ index proposed by Abul Naga and Geoffard (2006: $365)$. For the specific choice of their parameters $\alpha=\beta=1$, it turns out that we have $L=(\kappa-1) \mu_{h}$. It needs to be pointed out that in their social welfare framework, inspired by Tsui (1999), the parameters are constrained by the condition $\alpha+\beta \leq 1$.
} 
Since $M$ is at most equal to $2(n-1) / n$, it follows that these two amounts are bounded by $1-n$ and $n-1$. For the bounded version of the level-dependent index, the natural choice for the value of $A$ is therefore $A=1$.

Although the weighting function of index $L$ looks very similar to that of index $R$, the two indices are not identical (see Erreygers et al., 2018). A striking difference is that the pivotal position of the rank-dependent index (meaning the position for which the weighting function equals zero and changes sign) corresponds to the median income level, while that of the leveldependent index is constituted by the mean income level.

\section{Regression Approaches to Decomposition}

\subsection{The Conventional Approach}

Regression-based decomposition methods are now widely used in the analysis of socioeconomic inequality of health. The WDW approach has paved the way for a stream of studies in which the Concentration Index is decomposed in two steps based on regressions of health. The idea is to first start from a simple equation which explains the health variable in terms of the independent variables $x_{1}, x_{2}, \ldots, x_{q}$ :

$$
h_{i}=\lambda_{0}+\lambda_{1} x_{1, i}+\lambda_{2} x_{2, i}+\ldots+\lambda_{q} x_{q, i}+\varepsilon_{i}
$$

where $\varepsilon_{i}$ represents the error term for which the zero conditional mean assumption applies, i.e. $E\left(\varepsilon_{i} \mid x_{1, i}, \ldots, x_{q, i}\right)=0$. The right-hand side is then plugged into the formula for the Concentration Index instead of $h_{i}$. Applying the procedure to $(5)$, we obtain:

$$
R(\widetilde{f}, h)=\sum_{j=1}^{q} \hat{\lambda}_{j} R\left(\widetilde{f}, x_{j}\right)+R(\widetilde{f}, \hat{\varepsilon})
$$

Often the terms $\hat{\lambda}_{j} R\left(\widetilde{f}, x_{j}\right)$ are identified as the contributions of the variables $x_{j}$ to the measured amount of inequality $R(\tilde{f}, h)$, and the term $R(\tilde{f}, \hat{\varepsilon})$ as the unexplained part of the inequality.

Obviously, the same procedure can be applied to (7), which then yields:

$$
L(\widetilde{y}, h)=\sum_{j=1}^{q} \hat{\lambda}_{j} L\left(\widetilde{y}, x_{j}\right)+L(\widetilde{y}, \hat{\varepsilon})
$$

In previous work we have taken a critical look at a few aspects of this approach, and advocated caution in the interpretation of the results (Erreygers 
and Kessels, 2013; Kessels and Erreygers, 2016). Our main criticism is that an explanation of the association between two variables which is based on the determinants of only one of these variables, appears to be partial and incomplete, and may therefore lead to biased conclusions. Remaining in the framework of rank-dependent indicators, we also suggested a few alternatives. In this paper we go a step further and generalize one of the alternatives we suggested into a regression method which can be applied to both rank- and level-dependent indicators, but which has a slightly more intuitive interpretation in the latter case. Before we present this new regression method, we briefly look at the RIF regression method which has been introduced recently.

\subsection{The RIF Regression Approach}

Heckley, Gerdtham and Kjellsson (2016) applied the concept of RIF regression to the decomposition of rank-dependent indices. They built on the work by Firpo et al. (2007, 2009) who derived and decomposed RIFs for univariate measures of income inequality such as the variance, the unconditional quantile and the Gini index. The RIF is based on the influence function (IF), which is rooted in robust statistics (Hampel et al., 1986) and provides an approximation of the derivative of a statistic. For each individual a RIF value can be computed that denotes the individual's influence on the statistic. This value indicates how the statistic would change if that individual were to be removed from the sample. To decompose a particular rank-dependent index, one can compute the corresponding vector of RIF values using the formulas of Heckley, Gerdtham and Kjellsson (2016), which, in its turn, serves as the response variable in a linear regression model. As a result, one can estimate the marginal degrees of influence the explanatory variables have on the index. The approach has been applied by Cai, Coyte and Zhao (2017), who use the RIF regression decomposition method to examine income-related health inequality in China.

We present the discrete version of the formulas of Heckley, Gerdtham and Kjellsson (2016) for the IF and RIF for the rank-dependent index $R$. The IF is defined as

$$
I F_{i}^{R}=\mu_{h}-h_{i}-2 R+\widetilde{f}_{i} h_{i}-2 g l p_{i}
$$

where $g l p_{i}$ stands for the generalized Lorenz point of individual $i$, i.e. the absolute concentration curve coordinate of the individual. Given that individual $i$ does not belong to a tied income group (recall that we assume there are no income ties), the $g l p_{i}$ value is defined as follows:

$$
g l p_{i}=\frac{h_{i}+2 \sum_{j=0}^{i-1} h_{j}}{2 n}
$$


where we take $h_{0}=0 .^{5}$

The RIF for the rank-dependent index $R$ is obtained as the sum of the IF and the value for $R$, i.e.

$$
R I F_{i}^{R}=I F_{i}^{R}+R
$$

The regression equation for $R I F^{R}$ is given by

$$
R I F_{i}^{R}=\phi_{0}+\phi_{1} x_{1, i}+\phi_{2} x_{2, i}+\ldots+\phi_{q} x_{q, i}+\psi_{i}
$$

where $\phi_{0}$ is the intercept, $\phi_{1}, \phi_{2}, \ldots, \phi_{q}$ represent the marginal degrees of influence the explanatory variables have on $R$ and $\psi_{i}$ is the error term where $E\left(\psi_{i} \mid x_{1, i}, \ldots, x_{q, i}\right)=0$. As shown by Heckley, Gerdtham and Kjellsson (2016: 97), under the assumptions of a model form linear in the parameters with an additive error term and zero conditional mean of the error term, the regression coefficients denote marginal effects and the regression model (15) is optimally estimated using OLS.

We apply a similar procedure as in Heckley, Gerdtham and Kjellsson (2016) to compute the formulas for the IF and RIF for the level-dependent index $L$. We start from the covariance definition of $L$ (Erreygers and Kessels, 2017: Equation (26)):

$$
L=\frac{\operatorname{Cov}(y, h)}{\mu_{y}}
$$

We then apply the chain rule for influence functions to obtain the IF:

$$
I F_{i}^{L}=\left(\widetilde{y}_{i}-1\right)\left(h_{i}-\mu_{h}\right)-\widetilde{y}_{i} L
$$

The corresponding RIF is computed by adding the index $L$ to the IF so that

$$
R I F_{i}^{L}=\left(\widetilde{y}_{i}-1\right)\left(h_{i}-\mu_{h}-L\right)
$$

Finally, the regression equation for $R I F^{L}$ is

$$
R I F_{i}^{L}=\chi_{0}+\chi_{1} x_{1, i}+\chi_{2} x_{2, i}+\ldots+\chi_{q} x_{q, i}+\tau_{i}
$$

where $\chi_{0}$ is the intercept, $\chi_{1}, \chi_{2}, \ldots, \chi_{q}$ represent the marginal degrees of influence the explanatory variables have on $L$ and $\tau_{i}$ is the error term where $E\left(\tau_{i} \mid x_{1, i}, \ldots, x_{q, i}\right)=0$. Also here, the model is estimated using OLS.

\footnotetext{
${ }^{5}$ If individual $i$ belongs to a tied income group with $k+1$ members, $\{g, g+1, \ldots, g+k\}$, then the $g l p_{i}$ value of every individual of this group is equal to:

$$
g l p_{i}=\frac{\sum_{j=g}^{g+k} h_{j}+2 \sum_{j=0}^{g-1} h_{j}}{2 n}
$$
}




\subsection{A Direct Approach}

The WDW and RIF regression approaches to the decomposition of socioeconomic inequality of health are specific applications of techniques which can be used for the analysis of a wide variety of inequality and poverty indicators. By contrast, the method which we now present is developed specifically for the analysis of bivariate inequality indicators of the covariance type, and it cannot in any simple way be extended to other indicators. The method consists of a one-step approach that can be implemented directly from rewriting the index.

Let us begin with the (absolute version of the) level-dependent index. Observe that we can write index $L$ as:

$$
L=\frac{1}{n} \sum_{i=1}^{n}\left(\widetilde{y}_{i} h_{i}-\mu_{h}\right)
$$

Defining $d_{i}=\widetilde{y}_{i} h_{i}-\mu_{h}$, we arrive at the following extremely simple expression of the index:

$$
L=\frac{1}{n} \sum_{i=1}^{n} d_{i}=\mu_{d}
$$

The value of the $d$ variable can be interpreted as a numerical indicator of an individual's deviation from what we call the 'reference outcome' in the income-health domain. The reference outcome is defined as the situation in which an individual attains in each dimension the mean or expected level, i.e. when $\left(y_{i}, h_{i}\right)=\left(\mu_{y}, \mu_{h}\right)$. If individual $i$ reaches the reference outcome, we have $d_{i}=\frac{\mu_{y}}{\mu_{y}} \mu_{h}-\mu_{h}=0$. If an individual performs better than average on both income and health, then $d_{i}>0$; in the opposite case, we have $d_{i}<0$. If one of the two is higher than average but the other lower, the sign of $d_{i}$ is undetermined. If $\frac{y_{i} h_{i}}{\mu_{y} \mu_{h}}>1$, we have $d_{i}>0$, and this can be interpreted as indicating a situation which is on the whole better than the reference outcome. If, however, $\frac{y_{i} h_{i}}{\mu_{y} \mu_{h}}<1$, we have $d_{i}<0$, which can be seen as a situation which is on the whole worse than the reference outcome.

We treat an individual's $d$ value as a measure of how this individual performs overall, i.e. jointly for income and health, relative to society as a whole. If an individual performs worse than average in one dimension, this can be compensated by a strong performance in the other dimension. Since the inequality index $L$ is additive in the individual $d$ values, we consider these values to be the individual components of the index. It should be kept in mind that these components are of a relative nature; a change in an individual's health or income level affects not only the component of this 
individual, but also that of all other individuals, through its effect on average health or income.

The new decomposition method we propose here is based on a regression of the individual $d$ values. We see this as a more natural and direct procedure to explain the correlation between income and health than the one based on a regression of health only or the one based on the RIF regression. As a matter of fact, the $d$ values take into account both income and health, they constitute the individual components of the index, and by means of their average they capture the degree of association between income and health. Assume that we explain $d$ by means of the independent variables $x_{1}, x_{2}, \ldots, x_{q}$. More specifically, let us consider the linear regression equation:

$$
d_{i}=\gamma_{0}+\gamma_{1} x_{1, i}+\gamma_{2} x_{2, i}+\ldots+\gamma_{q} x_{q, i}+\varphi_{i}
$$

where $\varphi_{i}$ is the error term for which we assume zero conditional mean, $E\left(\varphi_{i} \mid x_{1, i}, \ldots, x_{q, i}\right)=0$. Similar as for RIF regression, the regression coefficients represent marginal effects and the regression specification (22) is optimally estimated using OLS. In general, the sign and significance of the coefficients $\gamma_{j}$ express the effect which the variables have on the individual components of the index. One certainly expects variables which are positively correlated with both income and health to have positive coefficients, since higher values of income and health are equivalent to higher values of $d$. By contrast, variables which are negatively correlated with both income and health are expected to have negative coefficients.

Plugging the estimates of (22) into (21), and taking into account that $\mu_{\hat{\varphi}}=0$, we obtain the following result:

$$
L=\hat{\gamma}_{0}+\hat{\gamma}_{1} \mu_{x_{1}}+\hat{\gamma}_{2} \mu_{x_{2}}+\ldots+\hat{\gamma}_{q} \mu_{x_{q}}
$$

Expression (23) can be used to assess the expected marginal effect of each independent variable on $L$. The estimated effect of a small ceteris paribus change $\Delta \mu_{x_{j}}$ of $\mu_{x_{j}}$ on $L$ is equal to $\hat{\gamma}_{j} \Delta \mu_{x_{j}}$. For comparable changes $\Delta \mu_{x_{j}}$ and $\Delta \mu_{x_{l}}$ of the variables $x_{j}$ and $x_{l}$, it is therefore possible to determine which of the two has the largest marginal effect on the index. What we definitely should not do, is to claim that the product $\hat{\gamma}_{j} \mu_{x_{j}}$ constitutes the contribution of variable $x_{j}$ to the observed level of inequality. If that were true, the contribution of any mean centered variable would automatically be zero. However, we can gain some insight into the importance of the independent variables by looking at the logworth values for regression equation (22). The logworth statistic, defined as $-\log _{10}(P$-value of the $F$-test $)$, measures the importance of one variable or a group of variables as a whole for which an $F$ - 
test has been performed. ${ }^{6}$ Logworth values are logarithmic transformations of the $P$-values from $F$-tests in order to compose a ranking of the variables' importances. They prove especially useful when handling $F$-tests that are extremely significant, which happens with large datasets. Logworth values are always positive. A logworth value of zero corresponds to an insignificant $P$-value of 1 , a logworth value of 1.3 to a $P$-value of 0.05 and any logworth value above two to a $P$-value below 0.01 . Logworth values of 100 and more correspond to extremely small $P$-values. Generally, larger effects lead to more significant $P$-values and larger logworth values, but this relationship does not always hold because significance also depends on the error variance. In effect, logworth values are based on $F$-tests that compare the explanatory power of the variable(s) to the error variance. The error variance is thus embedded in their computation.

Can the same approach also be applied to rank-dependent indicators? It can, with one important change. Let us start by observing that the rankdependent index $R$ may be expressed as:

$$
R=\frac{1}{n} \sum_{i=1}^{n}\left(\widetilde{f}_{i} h_{i}-\mu_{h}\right)
$$

The mean relative fractional income rank of an individual is equal to 1 , which corresponds to the individual with median income. By analogy with our approach of the level-dependent index, we can define the reference outcome as the situation in which an individual attains the average level of both relative fractional income rank and health. For an individual who reaches the reference outcome, the value of the expression between brackets in (24) is 0 . Defining $u_{i} \equiv \widetilde{f}_{i} h_{i}-\mu_{h}$, we can interpret $u_{i}>0$ as an indication that individual $i$ attains a situation in the income rank-health space which is on the whole better than the reference outcome, and $u_{i}<0$ as indicating a situation which is on the whole worse than the reference outcome.

Since we now have:

$$
R=\frac{1}{n} \sum_{i=1}^{n} u_{i}=\mu_{u}
$$

what we should do next is to explain $u$ by means of a set of independent variables. Suppose that we estimate the following regression using OLS:

$$
u_{i}=\beta_{0}+\beta_{1} x_{1, i}+\beta_{2} x_{2, i}+\ldots+\beta_{q} x_{q, i}+\eta_{i}
$$

\footnotetext{
${ }^{6}$ The name logworth was coined in 1995 by Padraic Neville in the specific context of decision tree criteria. The logworth statistic has been implemented in the JMP software product from SAS Institute, Cary, NC, USA.
} 
where we assume $E\left(\eta_{i} \mid x_{1, i}, \ldots, x_{q, i}\right)=0$. We then end up with the following counterpart of $(23)$ :

$$
R=\hat{\beta}_{0}+\hat{\beta}_{1} \mu_{x_{1}}+\hat{\beta}_{2} \mu_{x_{2}}+\ldots+\hat{\beta}_{q} \mu_{x_{q}}
$$

Also here, logworth values associated with regression equation (26) provide information on the importance of the (groups of) variables. They can be used for ranking the variables based on their impact on the model.

An important difference between the decomposition of $L$ and that of $R$, is that the reference outcome of individual $i$ in the first case corresponds to the mean income $\mu_{y}$ and the mean health $\mu_{h}$, but in the second to the mean income rank (and hence to the median rather than the mean income) and the mean health.

\subsection{Comparing the Different Approaches}

Before we apply the three different regression-based decomposition methods in practice, we wish to dig a little deeper to discover what distinguishes them. A first observation is that the response variables of their regressions are of a different nature: 'health' in the case of the WDW decomposition, 'influence on the indicator' in the case of the RIF decomposition, and 'overall outcome with respect to income and health' in the direct decomposition. This criterion clearly sets apart the WDW decomposition, since it looks at one of the variables only - health. In previous work (Erreygers and Kessels, 2013; Kessels and Erreygers, 2016) we have argued why we believe that a one-sided regression approach could yield biased decomposition results. The RIF and direct decompositions, by contrast, consider both variables jointly, and are therefore more promising.

This brings us to a second observation: there is an important difference between the response variables of the RIF and direct regressions. We show this by comparing the RIF values and the composite variable values for the level-dependent index $L$, respectively $R I F_{i}^{L}$ and $d_{i}$, and by providing a graphical illustration. From the definition of $R I F_{i}^{L}$ (see (18)) it follows that $R I F_{i}^{L}>0$ in two cases: high income and good health (i.e., when $\widetilde{y}_{i}>1$ and $\left.h_{i}>\mu_{h}+L\right)$, and low income and bad health (i.e., when $\widetilde{y}_{i}<1$ and $\left.h_{i}<\mu_{h}+L\right)$. Likewise, we have $R I F_{i}^{L}<0$ for individuals with high income and bad health $\left(\widetilde{y}_{i}>1\right.$ and $\left.h_{i}<\mu_{h}+L\right)$, or with low income and good health $\left(\widetilde{y}_{i}<1\right.$ and $\left.h_{i}>\mu_{h}+L\right)$. Figure 1 represents the situation of an individual with low income and bad health. Her $R I F_{i}^{L}$ is equal to the area of the shaded rectangle defined by the point representing her situation $\left(\widetilde{y}_{i}, h_{i}\right)$ and the point representing the reference situation $\left(1, \mu_{h}+L\right)$. For the composite 
variable we get something substantially different. As already explained, we have $d_{i}>0$ when $\widetilde{y}_{i} h_{i}>\mu_{h}$, and $d_{i}<0$ when $\widetilde{y}_{i} h_{i}<\mu_{h}$. For individuals with high income and good health (which now means $\widetilde{y}_{i}>1$ and $h_{i}>\mu_{h}$ ) we have $d_{i}>0$, but for individuals with low income and bad health $\left(\widetilde{y}_{i}<1\right.$ and $h_{i}<\mu_{h}$ ) we have $d_{i}<0$. Figure 2 represents the same individual as the one of Figure 1. Her $d_{i}$ value is a measure of the distance between two rectangular hyperbola. The first is defined by the equation $\widetilde{y} h=\mu_{h}$ and consists of all combinations of relative income $\widetilde{y}$ and health $h$ for which $d=0$, such as $\widetilde{y}=1$ and $h=\mu_{h}$. The second hyperbola is defined by the equation $\widetilde{y} h=\widetilde{y}_{i} h_{i}$ and consists of all combinations of relative income $\widetilde{y}$ and health $h$ for which $d=d_{i}$, such as $\widetilde{y}=\widetilde{y}_{i}$ and $h=h_{i}$. The $d_{i}$ value corresponds to the vertical distance between the second and the first hyperbola measured at the location $\widetilde{y}=1$.

What this analysis reveals is that there is an asymmetry between the RIF response and the composite variable response with regard to individuals with low income and bad health. The RIF values for these individuals are positive, just as those for individuals with high income and good health. In other words, the RIF response does not distinguish people who are doing badly in both dimensions and people who are doing well in both dimensions. The values of the composite variable, by contrast, are negative for individuals with low income and bad health and positive for individuals with high income and good health. This means that the composite variable response does not treat these individuals similarly; in fact, it treats them oppositely. By focusing on the influence of individual observations on the observed inequality measure, the RIF decomposition ignores whether this influence is exerted by individuals who are well-off in all respects or by those who are struggling. The direct decomposition does take this difference into account, and concentrates on the overall income-health outcome of individuals.

This has important implications for the coefficients of the regression equations. Suppose one of the explanatory variables is positively associated with both income and health. High values of this variable therefore tend to go together with positive values of the composite variable, and low values with negative values of the composite variable. As a result, the covariate and the response variable of the direct decomposition regression are definitely positively correlated, and we can expect the estimated coefficient of the variable to be positive. By contrast, since both high and low values of the covariate are associated with positive and similar values of the RIF response variable, the covariate is only weakly correlated with the RIF response variable, if at all. Hence, it is unclear what to expect from the sign of the regression coefficient. A similar conclusion holds in the case of an explanatory variable which is negatively associated with both income and health. On the whole, it 


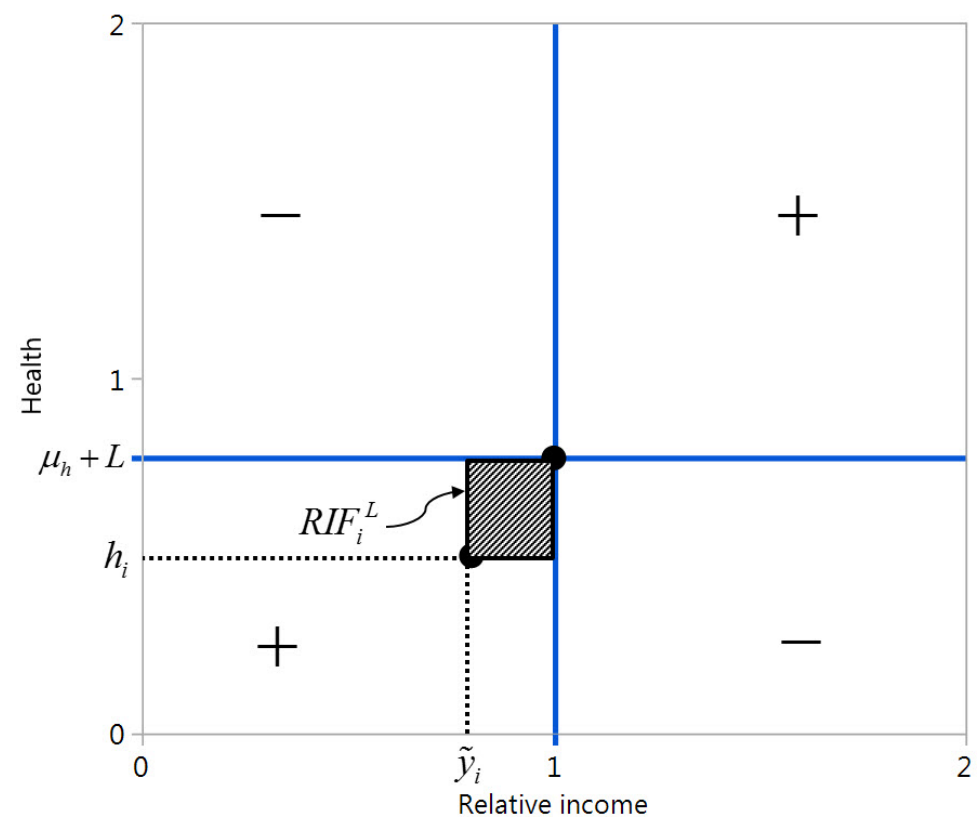

Figure 1: Illustration of the $R I F_{i}^{L}$ value for an individual with relative income $\widetilde{y}_{i}$ and health $h_{i}$.

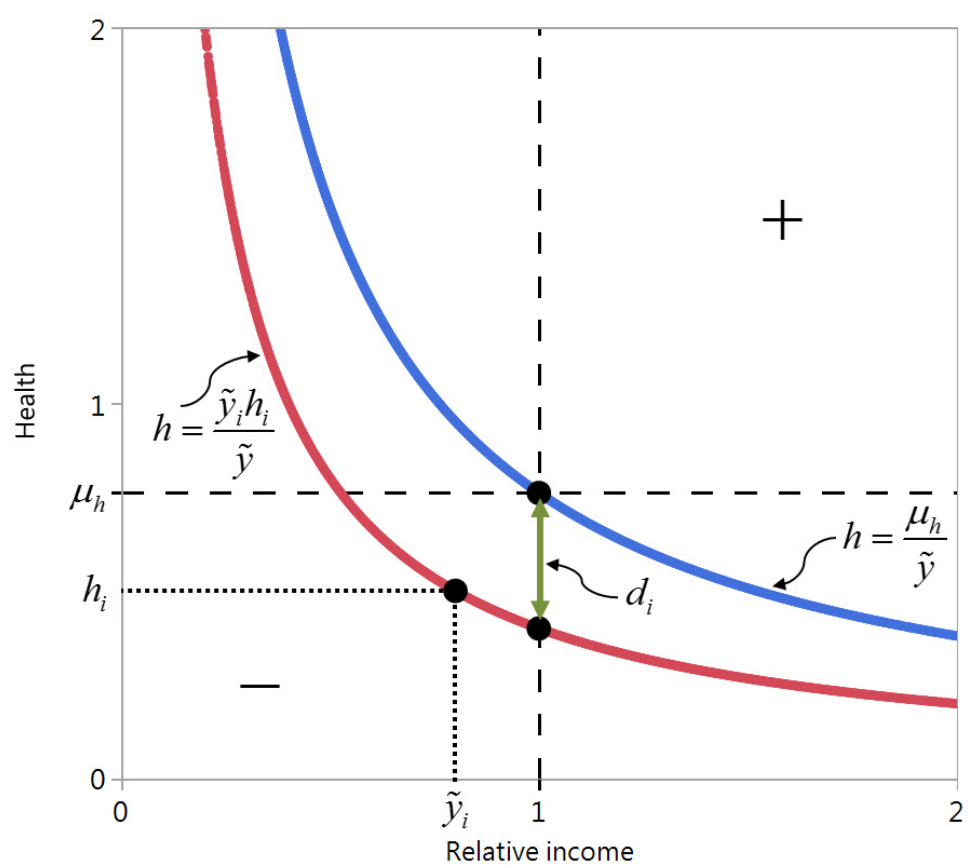

Figure 2: Illustration of the $d_{i}$ value for an individual with relative income $\widetilde{y}_{i}$ and health $h_{i}$. 
seems that the direct regression is better capable of revealing which variables have an undoubtedly positive or negative marginal effect on socioeconomic inequality of health than the RIF regression.

The choice is therefore between an influence-oriented method which decomposes income-related inequality based on an explanation of the statistical impact of individual observations, and a direct decomposition method based on an explanation of the overall positions of individuals in the income-health domain. We will now illustrate our findings by means of an empirical analysis.

\section{Empirical Application}

\subsection{Description of the Data}

The data come from Wave 13 of the Household, Income and Labour Dynamics in Australia (HILDA) survey, and were collected in 2013-2014. ${ }^{7}$ Our observations are individuals aged 15 years or older. Our income variable is equivalized income, calculated using the modified OECD equivalence scale (Australian Bureau of Statistics, 2013, Appendix 3). Each member of a household is assigned an equivalized income equal to the household's disposable income divided by its equivalence factor. This factor is obtained by giving the first adult of the household a score of 1 , every other adult a score of 0.5 , every child a score of 0.3 , and then adding up all the scores. Although children younger than 15 years are not included in the sample, they are incorporated in the calculation of the equivalized incomes. Our health variable is the SF-6D health score. Since this is a bounded variable, we use the bounded version of the inequality indices, $R^{b}$ and $L^{b}$. Given that the bounds of the variable are $h_{\min }=0$ and $h_{\max }=1$, it is easy to check that $R^{b}=4 R$ and $L^{b}=L$.

For our decomposition analysis we consider the following explanatory variables: sex, age, ancestry, occupational status, marital status, number of children, housing type, self-rated prosperity $^{8}$, life satisfaction, satisfac-

\footnotetext{
${ }^{7}$ More information on the HILDA database can be found here: https://www . melbourneinstitute.com/hilda/.

${ }^{8}$ This means people's satisfaction with their financial situation, which is fairly unrelated to income, as few Australians feel prosperous despite having a high income (see Hamilton and Barbato, 2005). The survey asked respondents the following: 'Given your current needs and financial responsibilities, would you say that you and your family are: prosperous, very comfortable, reasonably comfortable, just getting along, poor, very poor?' We grouped the first three categories into the category "living comfortably" and the last two categories into the category "living poorly".
} 
tion with weight, and lifestyle variables including smoking, time stress, sleep quality and physical activity. Our sample contains 14,728 individuals. ${ }^{9}$ The empirical work in Erreygers et al. (2018) has shown that this is a fairly large and representative sample, which does not require sample weights in the calculations. The composition of our sample is described in Table B1 in Appendix B.

\subsection{Regression Approaches to Decomposition: A Com- parison}

To begin with, we emphasize that the three regression approaches considered in this paper (the WDW, RIF and direct methods) yield results that are not all of the same nature. The conventional WDW approach is often used to estimate the relative contributions of different factors to the measured degree of socioeconomic inequality of health. These contributions, which can be either positive or negative, usually do not add up to 100\%. The difference, which again can be positive or negative, is accounted for by the residual term, which may be quite substantial. On the other hand, the RIF and the direct regression approaches differ from the WDW approach in the sense that they allow to estimate the marginal effects of the factors (and in particular their categories in the case of categorical factors) on the RIF of the observed inequality measure and on the inequality measure itself, respectively. In addition to their marginal effects, we are able to assess their importances by looking at the logworth values.

For the comparison of the three regression-based decomposition approaches, we need to estimate five regression equations. Each regression equation involves the same set of independent variables. While the dependent variable of the WDW regression is health $h$, those of the two RIF regressions are the RIFs for the bounded versions of the rank- and level-dependent indices, respectively $R I F-R^{b}$ and $R I F-L^{b}$, and those of the direct regressions the combined relative fractional income rank-health variable and the combined relative income-health variable, respectively $u$ and $d$. The independent variables are those mentioned in Table B1. Except for age, the number of children aged 0-4 and aged 5-14, and life satisfaction, which are numerical variables, all variables are categorical and enter into the regression equation as dummy variables. The reference situation is that of a female non-indigenous person,

\footnotetext{
${ }^{9}$ Note that we excluded individuals with a negative income. Furthermore, we classified 3,192 missing observations for ancestry as "non-indigenous", 4 for occupational status as "not in labour force", 104 for self-rated prosperity as "just getting along", 80 for satisfaction with weight as "neither satisfied/dissatisfied", 81 for smoking as "non-smoker", and 23 for time stress as "sometimes stressed".
} 
who provides a professional service, is married, lives in a house, lives comfortably, is neither satisfied/dissatisfied with her weight, does not smoke, is sometimes stressed for time, has a fairly good sleep quality, and does frequent physical activity. Table B2 in Appendix B provides summary statistics for the variables. Similar as in Erreygers et al. (2018), the values for the indices $R^{b}$ and $L^{b}$ equal 0.0657 and 0.0144 , respectively.

\subsubsection{WDW Regression Results}

The results of the regression for the health variable $h$ can be found in Table 1 , with the logworth values for the independent variables included for completeness. For the categorical variables, we provide these values for the associated dummy variables as a whole. The logworth values show that life satisfaction, sleep quality and occupational status are the most important determinants of health. They are followed by physical activity, time stress and age. Also, selfrated prosperity, satisfaction with weight and having young children (aged 0 -4) have a considerable effect on health. Of minor importance are having older children (aged 5-14), smoking, ancestry, marital status, sex and housing type. The regression coefficients $\hat{\lambda}_{j}$ suggest that being male, a manager or professional, having more children, a very good sleep quality, almost no stress, a greater life satisfaction, and being (very) satisfied with one's weight have positive effects on health; all other variables either have negative effects, or are insignificant at the $5 \%$ level.

The associated decompositions of the $R^{b}$ and $L^{b}$ indices are shown in Table 2. The contribution of variable $x_{j}$ to $R^{b}$ and $L^{b}$ depends on the estimated coefficient $\hat{\lambda}_{j}$ in Table 1 and on the indices $4 R\left(\widetilde{f}, x_{j}\right)$ and $L\left(\widetilde{y}, x_{j}\right)$. In the last column of each decomposition, the contributions are expressed as percentages; for the variables with more than two categories, such as housing type, occupational status and self-rated prosperity, these percentages are combined over the categories. Note that the choice of the reference category for the categorical variables does not have any impact on the percentages. The results for index $R^{b}$ are quite similar to those for index $L^{b}$. The largest contribution amounts to $41 \%$ for the $R^{b}$ index and to $37 \%$ for the $L^{b}$ index and is due to occupational status. This contribution is followed by self-rated prosperity ( $12 \%$ for $R^{b}$ and $13 \%$ for $\left.L^{b}\right)$ and by life satisfaction $\left(8 \%\right.$ for $R^{b}$ and $11 \%$ for $L^{b}$ ). Not surprisingly, this ranking is somewhat different from the one indicated by the logworth values for the health regression in Table 1. Also, the dummy variables of occupational status, except for the managers and professionals dummy, and those of self-rated prosperity tend to be negatively associated with health (as can be seen from the negative sign of the regression coefficients $\hat{\lambda}_{j}$ ) and characterized by a strong pro-poor distribution 
(as revealed by the indices $4 R\left(\widetilde{f}, x_{j}\right)$ and $\left.L\left(\widetilde{y}, x_{j}\right)\right)$. The managers and professionals dummy as well as life satisfaction show an opposite pattern. As far as the other variables are concerned, time stress and having a higher number of children contribute negatively to socioeconomic inequality. It must also be observed that the so-called unexplained part of the decomposition is quite substantial, viz. $23 \%$ for the $R^{b}$ index and $25 \%$ for the $L^{b}$ index.

\subsubsection{RIF Regression Results}

Tables 3 and 4 contain the decomposition results of the RIF regressions. Similar to what we did for the health regression, we calculated the logworth values and grouped the category dummies of the categorical variables together. A first observation is that the RIF regressions do not explain much of the variation in the RIFs, as indicated by the very small $R^{2}$ values ( $5 \%$ for $R I F-R^{b}$ and $4 \%$ for $\left.R I F-L^{b}\right)$ and the small logworth values, some of which are smaller than 1.3 indicating insignificance at the $5 \%$ level. Correspondingly, the estimation errors of the regressions are extremely large. ${ }^{10}$ Looking at the logworth values for $R I F-R^{b}$ and $R I F-L^{b}$, we observe similar importance rankings of the variables. Self-rated prosperity and employment status are most important for explaining the RIFs, followed by physical activity.

A study of the regressions' marginal effects shows that having more young children and a greater life satisfaction, being almost always, rarely and never stressed and very dissatisfied with one's weight, tend to have a negative effect on both $R I F-R^{b}$ and $R I F-L^{b}$, while all other variables have positive effects or are insignificant at the $5 \%$ level. Following the interpretation by Heckley, Gerdtham and Kjellsson (2016), this means, for instance, that an equal marginal increase in the life satisfaction for everyone in the population would have a negative impact on socioeconomic inequality of health. For most other variables (or their categories in the case of categorical variables) the impact would be positive or negligible.

\subsubsection{Direct Regression Results}

The regression results for the composite variables $u$ and $d$ are reported in Tables 5 and 6 . Compared to the RIF regressions, the direct regressions have substantially larger $R^{2}$ values (35\% for $u$ and $21 \%$ for $d$ ), larger logworth values (mostly much larger than 1.3 and thus greatly below the significance

\footnotetext{
${ }^{10}$ As an extra confirmation, the Root Mean Square Error (RMSE) of the regression for $R I F-R^{b}$ is 0.2773 which almost equals the RIF's standard deviation of 0.2849 , and the RMSE of the regression for $R I F-L^{b}$ is 0.0780 which also practically matches the RIF's standard deviation of 0.0796 .
} 
level of 5\%) and larger marginal effects, all indicative of greater explanatory power.

The logworth values from both direct regressions point toward the same important duo of explanatory variables as in the other decompositions, namely occupational status and self-rated prosperity. However, for the direct decompositions, marital status comes third. As far as the marginal effects are concerned, being male, a manager or professional, having a very good sleep quality and a greater life satisfaction, and being dissatisfied with one's weight, tend to have a positive effect on an individual's achievement in the income rank-health and income-health domains; all the other variables either have negative coefficients or are insignificant at the $5 \%$ level. We observe that these signs largely correspond to the ones of the indices $4 R\left(\widetilde{f}, x_{j}\right)$ and $L\left(\widetilde{y}, x_{j}\right)$ in Table 2. This implies that the directions of the associations between income and each of the explanatory variables seem to determine the signs of the direct regression coefficients. With regard to the magnitudes of the marginal effects, for both indices, we can say that the effects are the largest for individuals living in non-private dwellings, living poorly or who are just getting along, who are not in the labour force or unemployed, and a manager or professional. It deserves to be pointed out that the effects of these variables are all negative, except for the effect of the manager and professional dummy. This means that living in non-private dwellings, to give just one example, is associated with a pro-poor change of the indices. By contrast, being a manager or professional is associated with a pro-rich change of the indices.

\subsubsection{Comparing the RIF and Direct Response Variables}

In Section 3.4 we pointed out that there are profound differences in the way certain combinations of income and health are translated into values of the response variables of the RIF and direct regressions. This entails a lack of correlation between the two response variables. Table 7 shows the six correlation coefficients between the RIF responses and the composite variable responses used in the direct decompositions. While the correlations among the two RIF responses as well as among the two composite variable responses are large ( $82 \%$ and $80 \%$ ), the correlations between these two groups of responses are small or negligible.

There is an additional observation which deserves to be made when comparing the RIF and direct decomposition methods. When presenting the results of our empirical application, we pointed out that the RIF regressions have very low explanatory power. The $R^{2}$ value of the $R I F-R^{b}$ regression is a meagre 0.0548 and that of the $R I F-L^{b}$ regression even lower, 0.0405 . To put these numbers into perspective: the $R^{2}$ values of the regression of $u$ 
Table 1: The health regression

\begin{tabular}{l|rrrr}
\hline \hline Variable & \multicolumn{1}{|c}{$\hat{\lambda}_{j}$} & Prob $>|t|$ & Prob $>F$ & Logworth \\
\hline Male & 0.0045 & 0.0090 & & 2.048 \\
\hline Indigenous & -0.0209 & $<0.0001$ & & 4.111 \\
\hline Age & -0.0010 & $<0.0001$ & & 71.557 \\
\hline Not married & -0.0051 & 0.0071 & & 2.151 \\
\hline Children 0-4 & 0.0174 & $<0.0001$ & & 22.800 \\
\hline Children 5-14 & 0.0074 & $<0.0001$ & & \\
\hline Semi-detached house & -0.0057 & 0.0827 & & \\
Flat & -0.0037 & 0.1586 & & \\
Non-private dwelling & -0.0338 & 0.0404 & & \\
Other dwelling & -0.0103 & 0.3733 & 0.0575 & 1.240 \\
\hline Managers \& professionals & 0.0055 & 0.0164 & & \\
Manual workers & -0.0092 & 0.0035 & & \\
Unemployed & -0.0331 & $<0.0001$ & & \\
Not in labour force & -0.0547 & $<0.0001$ & $<0.0001$ & 164.348 \\
\hline Living poorly & -0.0403 & $<0.0001$ & & \\
Just getting along & -0.0219 & $<0.0001$ & $<0.0001$ & 35.975 \\
\hline Smoking & -0.0121 & $<0.0001$ & & 7.205 \\
\hline Very good sleep quality & 0.0278 & $<0.0001$ & & \\
Fairly bad sleep quality & -0.0369 & $<0.0001$ & & \\
Very bad sleep quality & -0.0794 & $<0.0001$ & \\
Not reported & -0.0428 & $<0.0001$ & $<0.0001$ & 178.856 \\
\hline Almost always stressed & -0.0341 & $<0.0001$ & & \\
Often stressed & -0.0199 & $<0.0001$ & & \\
Rarely stressed & 0.0218 & $<0.0001$ & \\
Never stressed & 0.0401 & $<0.0001$ & $<0.0001$ & \\
\hline Life satisfaction & 0.0199 & $<0.0001$ & & \\
\hline Very satisfied with weight & 0.0146 & $<0.0001$ & & \\
Satisfied with weight & 0.0038 & 0.0998 & & \\
Dissatisfied with weight & -0.0054 & 0.0144 & & \\
Very dissatisfied with weight & -0.0310 & $<0.0001$ & $<0.0001$ & \\
\hline No physical activity & -0.0593 & $<0.0001$ & & \\
Some physical activity & -0.0202 & $<0.0001$ & $<0.0001$ & 102.235 \\
\hline Constant & 0.6946 & $<0.0001$ & & \\
\hline$R^{2}$ & 0.3665 & & & \\
\hline \hline
\end{tabular}


Table 2: WDW decompositions of $R^{b}$ and $L^{b}$

\begin{tabular}{|c|c|c|c|c|c|c|}
\hline Variable & $4 R\left(\widetilde{f}, x_{j}\right)$ & $4 \hat{\lambda}_{j} R\left(\widetilde{f}, x_{j}\right)$ & $\%$ & $L\left(\widetilde{y}, x_{j}\right)$ & $\hat{\lambda}_{j} L\left(\widetilde{y}, x_{j}\right)$ & $\%$ \\
\hline Male & 0.0540 & 0.0002 & 0.37 & 0.0116 & 0.0001 & 0.36 \\
\hline Indigenous & -0.0294 & 0.0006 & 0.93 & -0.0067 & 0.0001 & 0.97 \\
\hline Age & -5.8245 & 0.0056 & 8.57 & -0.6138 & 0.0006 & 4.13 \\
\hline Not married & -0.2147 & 0.0011 & 1.67 & -0.0493 & 0.0003 & 1.76 \\
\hline Children $0-4$ & -0.0642 & -0.0011 & -1.70 & -0.0177 & -0.0003 & -2.14 \\
\hline Children 5-14 & -0.0626 & -0.0005 & -0.71 & -0.0164 & -0.0001 & -0.84 \\
\hline Semi-detached house & -0.0054 & 0.0000 & & 0.0011 & 0.0000 & \\
\hline Flat & -0.0204 & 0.0001 & & -0.0004 & 0.0000 & \\
\hline Non-private dwelling & -0.0067 & 0.0002 & & -0.0014 & 0.0000 & \\
\hline Other dwelling & -0.0066 & 0.0001 & 0.61 & -0.0014 & 0.0000 & 0.40 \\
\hline Managers \& professionals & 0.3587 & 0.0020 & & 0.0885 & 0.0005 & \\
\hline Manual workers & -0.0143 & 0.0001 & & -0.0083 & 0.0001 & \\
\hline Unemployed & -0.0464 & 0.0015 & & -0.0105 & 0.0003 & \\
\hline Not in labour force & -0.4245 & 0.0232 & 40.84 & -0.0817 & 0.0045 & 37.44 \\
\hline Living poorly & -0.0644 & 0.0026 & & -0.0135 & 0.0005 & \\
\hline Just getting along & -0.2567 & 0.0056 & 12.49 & -0.0631 & 0.0014 & 13.38 \\
\hline Smoking & -0.1105 & 0.0013 & 2.03 & -0.0274 & 0.0003 & 2.31 \\
\hline Very good sleep quality & 0.0182 & 0.0005 & & 0.0067 & 0.0002 & \\
\hline Fairly bad sleep quality & -0.0280 & 0.0010 & & -0.0086 & 0.0003 & \\
\hline Very bad sleep quality & -0.0267 & 0.0021 & & -0.0058 & 0.0005 & \\
\hline Not reported & -0.0091 & 0.0004 & 6.15 & -0.0020 & 0.0001 & 7.31 \\
\hline Almost always stressed & 0.0282 & -0.0010 & & 0.0048 & -0.0002 & \\
\hline Often stressed & 0.1031 & -0.0020 & & 0.0205 & -0.0004 & \\
\hline Rarely stressed & -0.1087 & -0.0024 & & -0.0222 & -0.0005 & \\
\hline Never stressed & -0.0303 & -0.0012 & -10.03 & -0.0056 & -0.0002 & -8.89 \\
\hline Life satisfaction & 0.2666 & 0.0053 & 8.07 & 0.0780 & 0.0016 & 10.79 \\
\hline Very satisfied with weight & -0.0029 & 0.0000 & & 0.0012 & 0.0000 & \\
\hline Satisfied with weight & -0.0299 & -0.0001 & & -0.0065 & 0.0000 & \\
\hline Dissatisfied with weight & 0.0736 & -0.0004 & & 0.0183 & -0.0001 & \\
\hline Very dissatisfied with weight & -0.0066 & 0.0002 & -0.53 & -0.0038 & 0.0001 & 0.07 \\
\hline No physical activity & -0.0888 & 0.0053 & & -0.0180 & 0.0011 & \\
\hline Some physical activity & 0.0010 & 0.0000 & 7.98 & -0.0028 & 0.0001 & 7.82 \\
\hline Residual term & 0.0153 & 0.0153 & 23.24 & 0.0036 & 0.0036 & 25.13 \\
\hline Total & & 0.0657 & 100.00 & & 0.0144 & 100.00 \\
\hline
\end{tabular}


Table 3: The regression for $R I F-R^{b}$

\begin{tabular}{|c|c|c|c|c|}
\hline Variable & $\hat{\phi}_{j}$ & Prob $>|t|$ & Prob $>F$ & Logworth \\
\hline Male & 0.0056 & 0.2428 & & 0.615 \\
\hline Indigenous & 0.0190 & 0.2001 & & 0.699 \\
\hline Age & 0.0007 & $<0.0001$ & & 5.492 \\
\hline Not married & 0.0154 & 0.0041 & & 2.388 \\
\hline Children 0-4 & -0.0159 & 0.0011 & & 2.954 \\
\hline Children 5-14 & 0.0060 & 0.0759 & & 1.120 \\
\hline Semi-detached house & 0.0352 & 0.0001 & & \\
\hline Flat & 0.0240 & 0.0011 & & \\
\hline Non-private dwelling & 0.0856 & 0.0655 & & \\
\hline Other dwelling & 0.0436 & 0.1811 & $<0.0001$ & 4.721 \\
\hline Managers \& professionals & 0.0261 & $<0.0001$ & & \\
\hline Manual workers & -0.0136 & 0.1242 & & \\
\hline Unemployed & 0.0045 & 0.7135 & & \\
\hline Not in labour force & 0.0665 & $<0.0001$ & $<0.0001$ & 27.327 \\
\hline Living poorly & 0.1523 & $<0.0001$ & & \\
\hline Just getting along & 0.0330 & $<0.0001$ & $<0.0001$ & 31.545 \\
\hline Smoking & 0.0091 & 0.1486 & & 0.828 \\
\hline Very good sleep quality & 0.0029 & 0.6408 & & \\
\hline Fairly bad sleep quality & 0.0077 & 0.2090 & & \\
\hline Very bad sleep quality & 0.0697 & $<0.0001$ & & \\
\hline Not reported & 0.0215 & 0.3120 & $<0.0001$ & 5.821 \\
\hline Almost always stressed & -0.0372 & $<0.0001$ & & \\
\hline Often stressed & -0.0041 & 0.4847 & & \\
\hline Rarely stressed & -0.0238 & 0.0002 & & \\
\hline Never stressed & -0.0549 & 0.0001 & $<0.0001$ & 7.170 \\
\hline Life satisfaction & -0.0073 & $<0.0001$ & & 4.326 \\
\hline Very satisfied with weight & -0.0062 & 0.4915 & & \\
\hline Satisfied with weight & -0.0014 & 0.8260 & & \\
\hline Dissatisfied with weight & -0.0039 & 0.5279 & & \\
\hline Very dissatisfied with weight & -0.0269 & 0.0039 & 0.0569 & 1.245 \\
\hline No physical activity & 0.0709 & $<0.0001$ & & \\
\hline Some physical activity & 0.0017 & 0.7346 & $<0.0001$ & 18.678 \\
\hline Constant & 0.0385 & 0.0372 & & \\
\hline$R^{2}$ & 0.0548 & & & \\
\hline
\end{tabular}


Table 4: The regression for $R I F-L^{b}$

\begin{tabular}{l|rrrr}
\hline \hline Variable & \multicolumn{1}{|c}{$\hat{\chi}_{j}$} & Prob $>|t|$ & Prob $>F$ & Logworth \\
\hline Male & 0.0021 & 0.1236 & & 0.908 \\
\hline Indigenous & 0.0081 & 0.0525 & & 1.280 \\
\hline Age & 0.0002 & $<0.0001$ & & 5.969 \\
\hline Not married & 0.0047 & 0.0020 & & 2.706 \\
\hline Children 0-4 & -0.0036 & 0.0081 & & 2.094 \\
\hline Children 5-14 & 0.0005 & 0.5733 & & 0.242 \\
\hline Semi-detached house & 0.0082 & 0.0016 & & \\
Flat & 0.0076 & 0.0002 & & \\
Non-private dwelling & 0.0269 & 0.0399 & & \\
Other dwelling & 0.0096 & 0.2950 & $<0.0001$ & 4.452 \\
\hline Managers \& professionals & 0.0090 & $<0.0001$ & & \\
Manual workers & -0.0036 & 0.1523 & & \\
Unemployed & 0.0055 & 0.1152 & & \\
Not in labour force & 0.0173 & $<0.0001$ & $<0.0001$ & 23.530 \\
\hline Living poorly & 0.0352 & $<0.0001$ & & \\
Just getting along & 0.0086 & $<0.0001$ & $<0.0001$ & 22.226 \\
\hline Smoking & 0.0031 & 0.0759 & & 1.120 \\
\hline Very good sleep quality & -0.0003 & 0.8709 & & \\
Fairly bad sleep quality & 0.0007 & 0.6645 & & \\
Very bad sleep quality & 0.0146 & $<0.0001$ & & \\
Not reported & 0.0025 & 0.6805 & 0.0012 & 2.926 \\
\hline Almost always stressed & -0.0076 & 0.0022 & & \\
Often stressed & -0.0006 & 0.6935 & & \\
Rarely stressed & -0.0056 & 0.0015 & & \\
Never stressed & -0.0123 & 0.0023 & $<0.0001$ & \\
\hline Life satisfaction & -0.0015 & 0.0033 & & \\
\hline Very satisfied with weight & 0.0015 & 0.5446 & & \\
Satisfied with weight & -0.0011 & 0.5491 & & \\
Dissatisfied with weight & -0.0018 & 0.2935 & & \\
Very dissatisfied with weight & -0.0053 & 0.0449 & 0.2227 & \\
\hline No physical activity & 0.0140 & $<0.0001$ & & \\
Some physical activity & 0.0004 & 0.7786 & $<0.0001$ & \\
\hline Constant & 0.0024 & 0.6457 & & \\
\hline$R^{2}$ & 0.0405 & & & \\
\hline \hline
\end{tabular}


Table 5: The regression for $u$

\begin{tabular}{l|rrrr}
\hline \hline Variable & \multicolumn{1}{|c}{$\hat{\chi}_{j}$} & Prob $>|t|$ & Prob $>F$ & Logworth \\
\hline Male & 0.1059 & $<0.0001$ & & 4.082 \\
\hline Indigenous & -0.4627 & $<0.0001$ & & 7.624 \\
\hline Age & -0.0118 & $<0.0001$ & & 43.927 \\
\hline Not married & -0.5479 & $<0.0001$ & & 73.560 \\
\hline Children 0-4 & -0.3080 & $<0.0001$ & & 28.794 \\
\hline Children 5-14 & -0.2149 & $<0.0001$ & & 29.399 \\
\hline Semi-detached house & -0.1011 & 0.0488 & & \\
Flat & -0.1601 & $<0.0001$ & & \\
Non-private dwelling & -1.2411 & $<0.0001$ & & \\
Other dwelling & -0.6246 & 0.0006 & $<0.0001$ & 9.461 \\
\hline Managers \& professionals & 0.7282 & $<0.0001$ & & \\
Manual workers & -0.3766 & $<0.0001$ & & \\
Unemployed & -0.9536 & $<0.0001$ & & \\
Not in labour force & -1.1957 & $<0.0001$ & $<0.0001$ & 537.449 \\
\hline Living poorly & -1.0707 & $<0.0001$ & & \\
Just getting along & -0.8882 & $<0.0001$ & $<0.0001$ & 192.907 \\
\hline Smoking & -0.2211 & $<0.0001$ & & 9.509 \\
\hline Very good sleep quality & 0.0816 & 0.0176 & & \\
Fairly bad sleep quality & -0.0896 & 0.0084 & & \\
Very bad sleep quality & -0.2335 & 0.0007 & \\
Not reported & -0.1828 & 0.1233 & $<0.0001$ & \\
\hline Almost always stressed & -0.0612 & 0.2152 & & \\
Often stressed & -0.0074 & 0.8207 & & \\
Rarely stressed & -0.1101 & 0.0018 & & \\
Never stressed & -0.1663 & 0.0369 & 0.0084 & \\
\hline Life satisfaction & 0.0957 & $<0.0001$ & & \\
\hline Very satisfied with weight & 0.0232 & 0.6445 & & \\
Satisfied with weight & -0.0219 & 0.5425 & & \\
Dissatisfied with weight & 0.1165 & 0.0008 & & \\
Very dissatisfied with weight & 0.0411 & 0.4288 & 0.0007 & \\
\hline No physical activity & -0.3524 & $<0.0001$ & & \\
Some physical activity & -0.1689 & $<0.0001$ & $<0.0001$ & \\
\hline Constant & 0.8566 & $<0.0001$ & & \\
\hline$R^{2}$ & 0.3547 & & & \\
\hline \hline
\end{tabular}


Table 6: The regression for $d$

\begin{tabular}{|c|c|c|c|c|}
\hline Variable & $\hat{\chi}_{j}$ & Prob $>|t|$ & Prob $>F$ & Logworth \\
\hline Male & 0.0260 & 0.0033 & & 2.488 \\
\hline Indigenous & -0.0967 & 0.0004 & & 3.418 \\
\hline Age & -0.0015 & $<0.0001$ & & 7.027 \\
\hline Not married & -0.1145 & $<0.0001$ & & 30.566 \\
\hline Children 0-4 & -0.0653 & $<0.0001$ & & 12.526 \\
\hline Children 5-14 & -0.0450 & $<0.0001$ & & 12.480 \\
\hline Semi-detached house & 0.0065 & 0.6999 & & \\
\hline Flat & -0.0007 & 0.9611 & & \\
\hline Non-private dwelling & -0.2691 & 0.0016 & & \\
\hline Other dwelling & -0.1340 & 0.0249 & 0.0044 & 2.361 \\
\hline Managers \& professionals & 0.2266 & $<0.0001$ & & \\
\hline Manual workers & -0.0893 & $<0.0001$ & & \\
\hline Unemployed & -0.1702 & $<0.0001$ & & \\
\hline Not in labour force & -0.2250 & $<0.0001$ & $<0.0001$ & 279.915 \\
\hline Living poorly & -0.2272 & $<0.0001$ & & \\
\hline Just getting along & -0.2163 & $<0.0001$ & $<0.0001$ & 103.965 \\
\hline Smoking & -0.0481 & $<0.0001$ & & 4.521 \\
\hline Very good sleep quality & 0.0232 & 0.0398 & & \\
\hline Fairly bad sleep quality & -0.0283 & 0.0113 & & \\
\hline Very bad sleep quality & -0.0547 & 0.0155 & & \\
\hline Not reported & -0.0505 & 0.1951 & 0.0006 & 3.213 \\
\hline Almost always stressed & -0.0197 & 0.2252 & & \\
\hline Often stressed & -0.0049 & 0.6489 & & \\
\hline Rarely stressed & -0.0302 & 0.0090 & & \\
\hline Never stressed & -0.0276 & 0.2919 & 0.0895 & 1.048 \\
\hline Life satisfaction & 0.0301 & $<0.0001$ & & 18.983 \\
\hline Very satisfied with weight & 0.0252 & 0.1268 & & \\
\hline Satisfied with weight & -0.0072 & 0.5408 & & \\
\hline Dissatisfied with weight & 0.0342 & 0.0028 & & \\
\hline Very dissatisfied with weight & -0.0022 & 0.8994 & 0.0012 & 2.910 \\
\hline No physical activity & -0.0886 & $<0.0001$ & & \\
\hline Some physical activity & -0.0470 & $<0.0001$ & $<0.0001$ & 10.845 \\
\hline Constant & 0.0368 & 0.2773 & & \\
\hline$R^{2}$ & 0.2111 & & & \\
\hline
\end{tabular}


Table 7: Coefficients of correlation between regression responses

\begin{tabular}{l|cccc}
\hline \hline & $R I F-R^{b}$ & $R I F-L^{b}$ & $u$ & $d$ \\
\hline$R I F-R^{b}$ & 1.00 & 0.82 & 0.01 & 0.04 \\
$R I F-L^{b}$ & & 1.00 & 0.00 & 0.16 \\
$u$ & & & 1.00 & 0.80 \\
$d$ & & & & 1.00 \\
\hline \hline
\end{tabular}

is 0.3547 and that of the regression of $d 0.2111$. It seems that the low $R^{2}$ values of the RIF regressions are due to a lack of variation in the response variables. The standard deviation of the $R I F_{i}^{R}$ variable is 0.2849 , while that of the $u$ variable is 1.9224 ; yet both response variables have the same mean, viz. $R^{b}=0.0657$. Likewise, the standard deviation of the $R I F_{i}^{L}$ variable is 0.0796 , much lower than that of the $d$ variable, 0.5711 , even though both have the same mean, viz. $L^{b}=0.0144$. This appears to be a general rule and not a peculiarity of the empirical case we have studied. It can even be shown that in some cases the RIF response variable is a constant, which means that the RIF regression is powerless. ${ }^{11}$

\section{Conclusion}

Summing up, in order to explain socioeconomic inequality of health, the direct decomposition method seems at least as promising as the WDW and the RIF decomposition methods. It improves upon the WDW method by relying on a regression of the joint outcome of income and health instead of on a regression of health only. And it is superior to the RIF method because it focuses on the deviation of the joint outcome from a reference position instead of on the influence of individual observations on the inequality index. A limitation of our paper is that we have restricted ourselves to the basic versions of the rank- and level-dependent indices. We are confident, however, that it will be possible to extend the approach to more general versions of the indices.

\footnotetext{
${ }^{11}$ Here is an example. Assume that $n$ is even and that there are no income ties. Let the $n / 2$ individuals with the lowest incomes all have health level $h^{-}$, and the $n / 2$ individuals with the highest incomes health level $h^{+}$, with $h^{-} \neq h^{+}$. Then we have $I F_{i}^{R}=0$ and therefore $R I F_{i}^{R}=R$ for all individuals in society. The $u_{i}$ values are not constant, however.
} 


\section{Appendix A. Sample Weights and Ties}

This appendix describes how the weights $w_{i}$ must be defined when working with datasets in which not all individuals have the same sample weight, and when there are ties between individuals in the income distribution.

Let us assume that the individuals of our dataset $(1,2, \ldots, n)$ are ranked according to their individual income, i.e. $y_{1} \leq y_{2} \leq \ldots \leq y_{n}$. We denote the sample weight of individual $i$ by $\sigma_{i}$, and we assume that $\sum_{i=1}^{n} \sigma_{i}=1$.

If there are ties in the income distribution, we define $k$ groups of individuals $G_{1}, G_{2}, \ldots, G_{k}$ such that everyone in group $G_{j}$ has income $y_{G_{j}}$, and moreover $y_{G_{1}}<y_{G_{2}}<\ldots<y_{G_{k}}$. The sample weight of group $G_{j}$ is $\sigma_{G_{j}}=\sum_{i \in G_{j}} \sigma_{i}$. The relative fractional rank of group $G_{j}$ is defined by the formula $\tilde{f}_{G_{j}} \equiv \sigma_{G_{j}}+2 \sum_{l=0}^{j-1} \sigma_{G_{l}}$, where we take $\sigma_{G_{0}}=0$ and $j=1, \ldots, k$.

Let individual $i$ belong to group $G_{j}$. Then the weight to be used for this individual in the calculation of the rank-dependent index is equal to:

$$
w_{i}^{R}=n \sigma_{i}\left(\widetilde{f}_{G_{j}}-1\right)
$$

As far as the level-dependent index is concerned, there is no need to consider the sample group weights. The weight of individual $i$ is equal to:

$$
w_{i}^{L}=n \sigma_{i}\left(\widetilde{y}_{i}-1\right)
$$

\section{Appendix B. Sample Statistics}

This appendix provides the tables with the sample statistics of the dataset used in the empirical application of Section 4. 
Table B1: Descriptive statistics of the sample $(\mathrm{N}=14,728)$

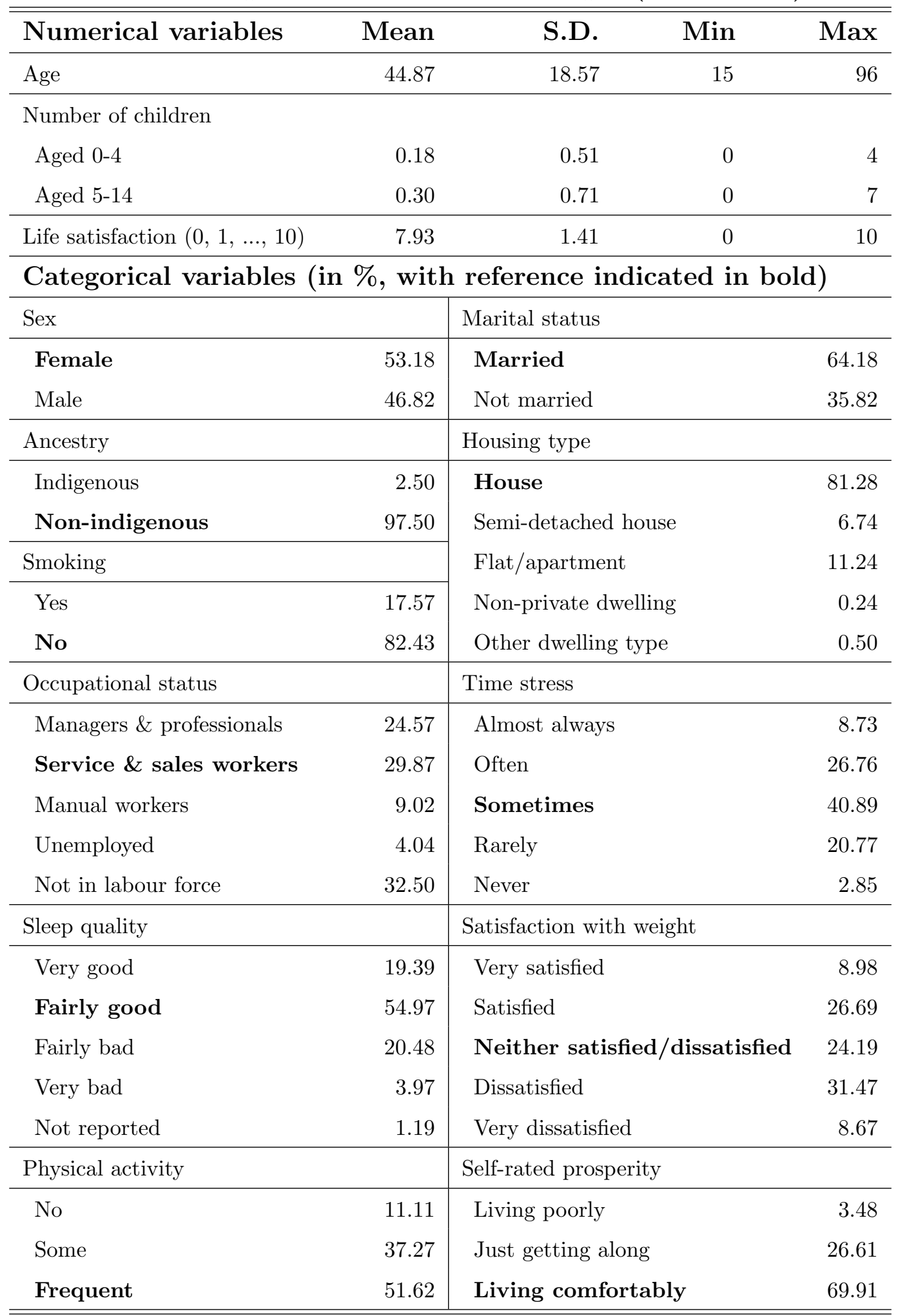


Table B2: Summary statistics for the variables

\begin{tabular}{l|cc|cc}
\hline \hline & \multicolumn{2}{|c|}{ Health } & \multicolumn{2}{c}{ Income $(\$)$} \\
\hline Variable & Mean & S.D. & Mean & S.D. \\
\hline Sex & 0.7508 & 0.1244 & 50,014 & 34,726 \\
Female & 0.7718 & 0.1216 & 52,394 & 35,102 \\
Male & & & & \\
\hline Ancestry & 0.7309 & 0.1375 & 37,429 & 21,193 \\
Indigenous & 0.7614 & 0.1231 & 51,480 & 35,133 \\
Non-indigenous & & & & \\
\hline Marital status & 0.7658 & 0.1195 & 55,058 & 35,959 \\
Married & 0.7512 & 0.1300 & 44,087 & 31,791 \\
Not married & & & & \\
\hline Number of children* & 0.7821 & 0.1145 & 47,050 & 26,270 \\
Aged 0-4 & 0.7679 & 0.1210 & 48,811 & 29,359 \\
Aged 5-14 & 0.6497 & 0.1437 & 31,339 & 17,358 \\
\hline Housing type & 0.7222 & 0.1294 & 39,006 & 20,940 \\
House & 0.7808 & 0.1134 & 56,728 & 38,156 \\
Semi-detached house & 0.7523 & 0.1260 & 51,958 & 41,341 \\
Flat/apartment & 0.7553 & 0.1281 & 50,966 & 41,969 \\
Non-private dwelling & 0.6772 & 0.1408 & 21,399 & 14,107 \\
Other dwelling type & 0.7280 & 0.1253 & 36,750 & 23,051 \\
\hline Occupational status & & & & \\
Managers \& professionals & 0.7896 & 0.1056 & 69,557 & 40,895 \\
Service \& sales workers & 0.7852 & 0.1094 & 53,184 & 29,142 \\
Manual workers & 0.7771 & 0.1146 & 46,415 & 20,954 \\
Unemployed & 0.7406 & 0.1313 & 37,811 & 23,340 \\
Not in labour force & 0.7140 & 0.1351 & 38,273 & 32,631 \\
\hline Self-rated prosperity & & & & \\
\hline
\end{tabular}

*Results for the number of individuals with children aged 0-4 (1,976) and with children aged 5-14 (2,789). 
Table B2 (Continued)

\begin{tabular}{l|cc|cc}
\hline \hline & \multicolumn{2}{|c|}{ Health } & \multicolumn{2}{c}{ Income $(\$)$} \\
\hline Variable & Mean & S.D. & Mean & S.D. \\
\hline Smoking & & & & \\
Yes & 0.7328 & 0.1314 & 43,153 & 28,402 \\
No & 0.7665 & 0.1210 & 52,828 & 35,932 \\
\hline Sleep quality & & & & \\
Very good & 0.8159 & 0.1060 & 52,898 & 40,367 \\
Fairly good & 0.7719 & 0.1117 & 52,031 & 34,993 \\
Fairly bad & 0.7076 & 0.1255 & 48,982 & 29,942 \\
Very bad & 0.6225 & 0.1363 & 43,665 & 29,095 \\
Not reported & 0.7076 & 0.1440 & 42,443 & 26,528 \\
\hline Time stress & & & & \\
Almost always & 0.7149 & 0.1293 & 53,941 & 31,630 \\
Often & 0.7473 & 0.1217 & 55,036 & 34,747 \\
Sometimes & 0.7667 & 0.1186 & 51,445 & 34,167 \\
Rarely & 0.7807 & 0.1227 & 45,672 & 35,299 \\
Never & 0.7912 & 0.1459 & 41,024 & 45,665 \\
\hline Satisfaction with weight & 0.7606 & 0.1236 & 51,129 & 34,922 \\
Very satisfied & 0.8027 & 0.1156 & 51,810 & 38,589 \\
Satisfied & 0.7748 & 0.1214 & 49,876 & 34,736 \\
Neither satisfied/dissatisfied & 0.7643 & 0.1225 & 49,196 & 32,567 \\
Dissatisfied & 0.7525 & 0.1187 & 54,093 & 36,922 \\
Very dissatisfied & 0.6924 & 0.1286 & 48,910 & 29,205 \\
\hline Physical activity & & & & \\
No & 0.6752 & 0.1416 & 42,845 & 33,565 \\
Some & 0.7505 & 0.1185 & 50,740 & 34,244 \\
Frequent & 0.7862 & 0.1132 & 53,192 & 35,420 \\
\hline
\end{tabular}




\section{References}

[1] Abul Naga, R.H. and P.-Y. Geoffard (2006), "Decomposition of bivariate inequality indices by attributes", Economics Letters, 90: 362-367.

[2] Allanson, P. and D. Petrie (2013), "Longitudinal methods to investigate the role of health determinants in the dynamics of income-related health inequality", Journal of Health Economics, 32: 922-937.

[3] Australian Bureau of Statistics (2013), Household Income and Income Distribution, Australia, 2011-12, Canberra, ABS, Catalogue No. 6523.0.

[4] Blinder, A. (1973), "Wage discrimination: reduced form and structural estimates", Journal of Human Resources, 8: 945-957.

[5] Bourguignon, F. (1979), "Decomposable income inequality measures", Econometrica, 47: 901-920.

[6] Cai, J., P.C. Coyte and H. Zhao (2017), "Decomposing the causes of socioeconomic-related health inequality among urban and rural populations in China: a new decomposition approach", International Journal for Equity in Health, 16: 128.

[7] Clarke, P., U.-G. Gerdtham and L.B. Connelly (2003), "A note on the decomposition of the health concentration index", Health Economics, 12: $511-516$.

[8] Erreygers, G. (2009), "Correcting the concentration index", Journal of Health Economics, 28: 504-515.

[9] Erreygers, G., P. Clarke and T. Van Ourti (2012), "Mirror, mirror, on the wall, who in this land is fairest of all?' - Distributional sensitivity in the measurement of socioeconomic inequality of health", Journal of Health Economics, 31: 257-270.

[10] Erreygers, G. and R. Kessels (2013), "Regression-based decompositions of rank-dependent indicators of socioeconomic inequality of health", in: P. Rosa Dias and O. O'Donnell (Eds.), Health and Inequality (Research on Economic Inequality, Volume 21), Emerald, pp. 227-259.

[11] Erreygers, G. and R. Kessels (2017), "Socioeconomic status and health: A new approach to the measurement of bivariate inequality", International Journal of Environmental Research and Public Health, 14: 673. 
[12] Erreygers, G., R. Kessels, L. Chen and P. Clarke (2018), "Subgroup decomposability of income-related inequality of health, with an application to Australia", Economic Record, 94: 39-50.

[13] Erreygers, G. and T. Van Ourti (2011), "Measuring socioeconomic inequality in health, health care, and health financing by means of rankdependent indices: A recipe for good practice", Journal of Health Economics, 30: 685-694.

[14] Essama-Nssah, B. and P.J. Lambert (2012), "Influence functions for policy impact analysis", in: J.A. Bishop and R. Salas (Eds.), Inequality, Mobility and Segregation: Essays in Honor of Jacques Silber (Research on Economic Inequality, Volume 20), Emerald, pp. 135-159.

[15] Essama-Nssah, B. and P.J. Lambert (2016), "Counterfactual decomposition of pro-poorness using influence functions", Journal of Human Development and Capabilities, 17: 74-92.

[16] Firpo, S., N.M. Fortin and T. Lemieux (2007), Decomposing Wage Distributions Using Recentered Influence Function Regressions, Working Paper presented at the 2007 NBER (National Bureau of Economic Research) Summer Institute.

[17] Firpo, S., N.M. Fortin and T. Lemieux (2009), "Unconditional quantile regressions", Econometrica, 77: 953-973.

[18] Hamilton, C. and C. Barbato (2005), "Why Australians Will Never Be Prosperous", Australian Institute Webpaper July 2005.

[19] Hampel, F.R, E.M. Ronchetti, P.J. Rousseeuw and W.A. Stahel (1986), Robust Statistics: The Approach Based on Influence Functions, John Wiley \& Sons.

[20] Heckley, G., U.-G. Gerdtham and G. Kjellsson (2016), "A general method for decomposing the causes of socioeconomic inequality in health", Journal of Health Economics, 48: 89-106.

[21] Kessels, R. and G. Erreygers (2016), "Structural equation modeling for decomposing rank-dependent indicators of socioeconomic inequality of health: an empirical study", Health Economics Review, 6: 56.

[22] Makdissi, P., D. Sylla and M. Yazbeck (2013), "Decomposing health achievement and socioeconomic health inequalities in presence of multiple categorical information", Economic Modelling, 35: 964-968. 
[23] Mehran, F. (1976), "Linear measures of income inequality", Econometrica, 44: 805-809.

[24] Oaxaca, R.L. (1973), "Male-female wage differentials in urban labor markets", International Economic Review, 14: 693-709.

[25] O'Donnell, O., E. Van Doorslaer and A. Wagstaff (2012), "Decomposition of inequalities in health and health care", in: A.M. Jones (Ed.), The Elgar Companion to Health Economics, Second Edition, Cheltenham, Edward Elgar, chapter 17, pp. 179-191.

[26] Rao, V.M. (1969), "Two decompositions of concentration ratio", Journal of the Royal Statistical Society, Series A (General), 132: 418-425.

[27] Shorrocks, A.F. (1980), "The class of additively decomposable inequality measures", Econometrica, 48: 613-625.

[28] Tsui, K. (1999), "Multidimensional inequality and multidimensional generalized entropy measures: An axiomatic derivation", Social Choice and Welfare, 16: 145-157.

[29] Van Doorslaer, E. and T. Van Ourti (2011), "Measuring inequality and inequity in health and health care", in: S. Glied and P.C. Smith (Eds.), The Oxford Handbook of Health Economics, Oxford, Oxford University Press, chapter 35, pp. 837-869.

[30] Van Ourti T., G. Erreygers and P. Clarke (2014), "Measuring equality and equity in health and health care", in: A.J. Culyer (Ed.), Encyclopedia of Health Economics, San Diego: Elsevier, Vol. 2, pp. 234-239.

[31] Van Ourti, T., E. Van Doorslaer and X. Koolman (2009), "The effect of income growth and inequality on health inequality: Theory and empirical evidence from the European Panel", Journal of Health Economics, 28: $525-539$.

[32] Wagstaff, A. (2005a), "The bounds of the concentration index when the variable of interest is binary, with an application to immunization inequality", Health Economics, 14: 429-432.

[33] Wagstaff, A. (2005b), "Inequality decomposition and geographic targeting with applications to China and Vietnam", Health Economics, 14: 649-635. 
[34] Wagstaff, A., E. Van Doorslaer and N. Watanabe (2003), "On decomposing the causes of health sector inequalities with an application to malnutrition inequalities in Vietnam", Journal of Econometrics, 112: 207-223. 


\title{
A Direct Regression Approach to Decomposing Socioeconomic Inequality of Health
}

\author{
Roselinde Kessels \\ Department of Economics, University of Antwerp \\ \& Flemish Research Foundation (FWO) \\ School of Economics, University of Amsterdam \\ City Campus, Prinsstraat 13 \\ 2000 Antwerp, Belgium \\ roselinde.kessels@uantwerpen.be \\ Tel. $+32(0) 32654095$ \\ Guido Erreygers \\ *Corresponding author \\ Department of Economics, University of Antwerp \\ Centre for Health Policy, University of Melbourne \\ City Campus, Prinsstraat 13 \\ 2000 Antwerp, Belgium \\ guido.erreygers@uantwerpen.be \\ Tel. +32 (0)32654052
}

Running title: Direct Decomposition of Inequality

Acknowledgements: This paper uses unit record data from the Household, Income and Labour Dynamics in Australia (HILDA) Survey. The HILDA Project was initiated and is funded by the Australian Government 
Department of Families, Housing, Community Services and Indigenous Affairs (FaHCSIA) and is managed by the Melbourne Institute of Applied Economic and Social Research (Melbourne Institute). The findings and views reported in this paper, however, are those of the authors and should not be attributed to either FaHCSIA or the Melbourne Institute. We acknowledge the Flemish Research Foundation (FWO) for Roselinde Kessels' postdoctoral fellowship. We are grateful to Linda Chen and Philip Clarke for their input in the initial stages of the work on this paper, to Gawain Heckley and Gustav Kjellsson for providing us with the Stata code for RIF regression of the concentration index, and to George Luta for detailed comments on a previous version. We also express our gratitude to two anonymous reviewers and the editor for their extensive comments and suggestions, which have led to substantial improvements. The paper has been presented at the international conference "Trends in inequality: social, economic and political issues" (Bologna) and in research seminars at Georgetown University (Washington) and Erasmus University (Rotterdam). We thank everyone who commented upon the paper. All errors are our responsibility.

Conflict of interest: The authors have no conflicts of interest to declare. 


\section{University Library}

\section{- M M N E R VA A gateway to Melbourne's research publications}

Minerva Access is the Institutional Repository of The University of Melbourne

Author/s:

Kessels, R;Erreygers, G

Title:

A direct regression approach to decomposing socioeconomic inequality of health

Date:

2019-07-01

Citation:

Kessels, R. \& Erreygers, G. (2019). A direct regression approach to decomposing socioeconomic inequality of health. HEALTH ECONOMICS, 28 (7), pp.884-905. https:// doi.org/10.1002/hec.3891.

Persistent Link:

http://hdl.handle.net/11343/286883 